\title{
Towards Green Cements: The Metakaolin Route
}

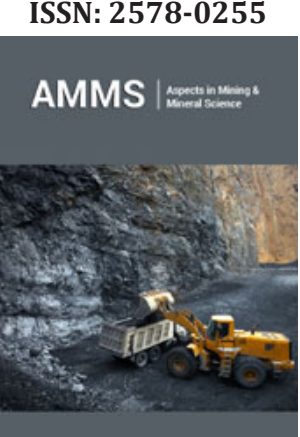

*Corresponding author: Henry F Meier, Department of Chemical Engineering, University of Blumenau, 3250 São Paulo Street, 89030-000 Blumenau, Brazil

Submission: 盟 March 03, 2020

Published: 㭰 May 29, 2020

Volume 5 - Issue 1

How to cite this article: Leonardo $M$ Rosa, Jonathan Utzig, Henry F Meier. Towards Green Cements: The Metakaolin Route. Aspects Min Miner Sci. 5(1). AMMS.000602. 2020.

DOI: 10.31031/AMMS.2020.05.000602

Copyright@ Henry F Meier, This article is distributed under the terms of the Creative Commons Attribution 4.0 International License, which permits unrestricted use and redistribution provided that the original author and source are credited.

\author{
Leonardo M Rosa, Jonathan Utzig and Henry F Meier* \\ Department of Chemical Engineering, Brazil
}

Opinion

One of the main challenges to be faced by the industry in this 21st century is the drastic reduction of its gaseous emissions, whether with the presence of particulate matter or substances that are aggressive to the environment. Both are problems found in the cement industry, which is responsible for up to $7 \%$ of carbon dioxide emissions produced by industrial human activity, which leads to the greenhouse effect [1]. This is due to two reasons: the first is that the raw material used for the production of clinker in rotary cement kilns is the limestone that undergoes a high temperature decarbonation reaction, with the transformation of carbonates into oxides and $\mathrm{CO}_{2}$ emission in the gaseous form, releasing fossilized carbon that had been purged from the natural carbon cycle in the atmosphere; the second is that the thermal energy used to supply the energy demand for the reactions comes from the use of solid fossil fuels such as petroleum coke. The $\mathrm{CO}_{2}$ average rate production is of the order of $800 \mathrm{~kg}$ of $\mathrm{CO}_{2} /$ ton of cement, due to the calcination of limestone. Of this amount, $50 \%$ comes from decarbonation and $40 \%$ from burning fossil fuels to supply energy demand. Efforts have been made to reduce emission rates, such as the use of biofuels, increase of clays in the raw material, and absorption of $\mathrm{CO}_{2}$ emissions. An alternative that has been evaluated is the use of pozzolanic clays in a reactive state as supplementary material [2], a technology that has been developed but which is not yet widely applied in the cement industry. The calcination of clays promotes the dehydroxylation of the molecules by the action of heat, forming only water vapor as a gaseous emission and an amorphous material called metakaolin. Metakaolin is highly reactive with water and forms a higher concentration of porous, low density spheres, with high absorption capacity and large surface area, suitable for clinker replacement. Metakaolin is known as low carbon cement, or "green cement", and can be used as a substitute or as an additive to conventional cement since it has better pozzolanic properties than Portland cement, such as [3]: increased resistance to compression and flexion, chemical attack and durability; the decrease in alkali-silica permeability and reactivity; facilitating the application of concrete, improves finish and appearance. In addition to the precursor kaolin, metakaolin can be obtained from recycled paper sludge, thus responding to more than one environmental appeal.

The calcination process of clays can be carried out in different ways, but the most promising is the "flash" calcination, in which the particulate solid kaolin is exposed to a gas stream at high temperature $\left(500-900^{\circ} \mathrm{C}\right)$ and in an adequate proportion for a few seconds, being cooled quickly afterwards $[4,5]$. Another way of production is through slow calcination in rotary kilns or in fixed beds ("soak calcination"), which requires residence times in the order of tens of minutes to hours due to low heating rates. San Nicolas et al. [5] noted that the metakaolin produced by the "flash" process, with a temperature between 600 and 700 ${ }^{\circ} \mathrm{C}$, contained a greater amount of spherical particles compared to that produced in a rotary kiln, which made it easier to apply, in addition to finding no significant difference regarding the pozzolanic activity of the products of each process. Claverie et al. [6] also found that the spherical particles were composed of gases and aluminosilicates with varied crystallinity. This heterogeneity was credited to the temperature gradient and the cyclonic movement of the flow in the calciner. By controlling the particles residence time in the calciner, different degrees of reactivity and dehydroxylation can be obtained. However, when exposed to temperatures greater than $900{ }^{\circ} \mathrm{C}$ and/or maintained for an excessive period in the calciner, 
metakaolin changes to other physical forms such as amorphous silica, mullite and glassy/crystalline silica. These latter compounds are no longer interesting as supplementary material, since they lose pozzolanic activity. Since kaolin calcination requires greater control of the mass ratio between hot gases and kaolin, temperature and residence time of the particles, its large-scale production becomes an engineering challenge. If this process is not well controlled, metakaolin can be transformed into undesirable materials. Still, the optimum temperature and calcination period are not yet known [7]. Investigations of the thermofluidodynamics of this reaction system, therefore, are fundamental for the deep understanding of calcination and, consequently, to advance in the development of this technology. However, greater attention has been paid to mathematical models for calcination of limestone, a fundamental raw material for cement, than for kaolin calcination. Possibly the first attempt in this direction was made by Salvador and Davies [8,9]. Teklay et al. [9] proposed a mathematical model for the chemical and physical conversions that occur in the kaolinitic clay particle, and subsequently evaluated the "flash" calcination in a pilot-scale reactor [9].

Numerous experimental studies of dehydroxylation in a rapid reaction system ("flash") with clays from different regions of Brazil have been carried out, showing that the process is technically and economically viable. Given that experimental tests have already been carried out successfully on a pilot scale, the transfer of this knowledge to industrial application remains, which requires a methodology adjusted for the complex calcination of kaolin in large scale. The proper investigations of reactors with large geometric proportions can be done using the Computational Fluid Dynamics (CFD) technique. In this sense, simulations are performed with a reactive multiphase model, capable of predicting in detail the pressure, velocity, temperature and chemical species concentration under reactive and turbulent conditions with heat and mass transfer. (Figure 1) presents simulation results of the rotary flow of kaolin and hot gases in an innovative configuration of calciner, in which a good thermal exchange is observed between the phases with the upward transport. Combining CFD simulations with optimization techniques, it is possible to define the geometric details of the reactor in order to guarantee an adequate configuration to leave the scale of the pilot plant where $\mathrm{kg} / \mathrm{h}$ are produced, for the industrial prototype scale with ton/h production of metakaolin. Metakaolin appears as an attractive and viable alternative for cement

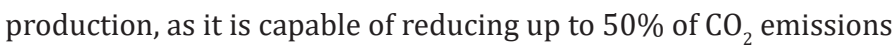
without drastic changes in the industrial park $[10,11]$. Numerical simulations can be used to evaluate the scale-up of the metakaolin production process, bringing it to high-tech status, hence facilitating the mitigation of $\mathrm{CO}_{2}$ emissions by replacing limestone calcination with the production of low carbon cement.

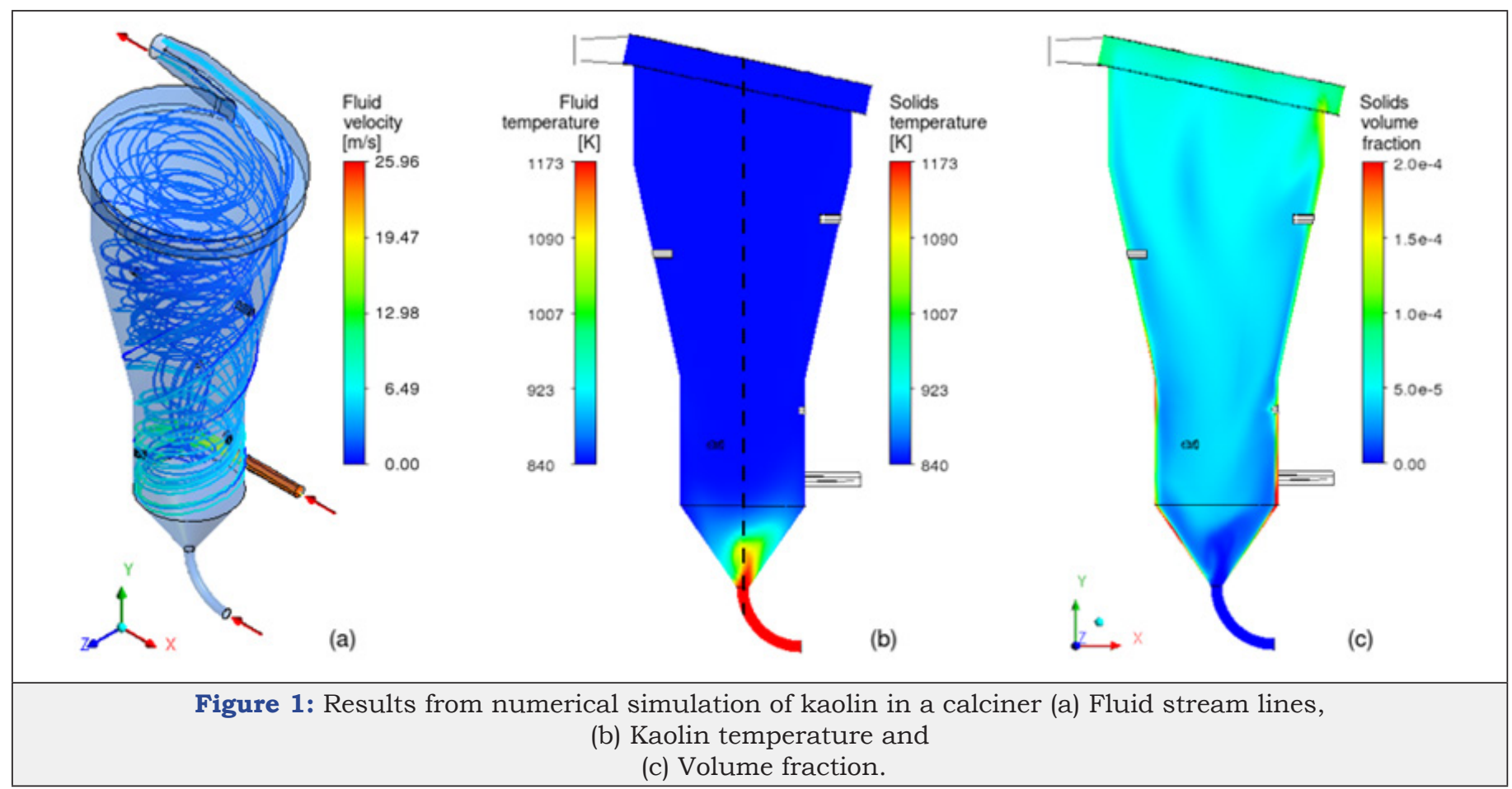

\section{Acknowledgment}

The authors gratefully acknowledge the financial support from FAPESC (code 2018TR1532) for this research.

\section{References}

1. Worrell E, Price L, Martin N, Hendriks C, Meida LO (2001) Carbon dioxide emissions from the global cement industry. Annual Review of Environment and Resources 26: 303-329.
2. Bridson D, Daavies T, Harrison D (1985) Properties of flash-calcined kaolinite. Clays and Clay Minerals 33(3): 258-260.

3. Teklay A, Yin C, Rosendahl L, Bojer M (2014) Calcination of kaolinite clay particles for cement production: A modeling study. Cement and Concrete Research 61-62: 11-19.

4. Salvador S, Pons O (2000) A semi-mobile flash dryer/calciner unit to manufacture pozzolana from raw clay soils -application to soil stabilization. Construction and Building Materials 14: 109-117. 
5. San Nicolas R, Cyr M, Escadeillas G (2013) Characteristics and applications of ash metakaolins. Applied Clay Science 83(84): 253-262.

6. Claverie M, Martin F, Tardy JP, Cyr M, De Parseval P, et al. (2015) Structural and chemical changes in kaolinite caused by flash calcination: Formation of spherical particles. Applied Clay Science 114: 247-255.

7. Rashad AM (2013) Metakaolin as cementitious material: History, scours, production and composition-A comprehensive overview. Construction and Building Materials 41: 303-318.

8. Salvador S, Davies TW (1994) Modeling of combined heating and dehydroxylation of kaolinite particles during flash calcination production of metakaolinite. Process Adv Mater 9: 128-135.
9. Teklay A, Yin C, Rosendahl L, Kohler LL (2015) Experimental and modeling study of flash calcination of kaolinite rich clay particles in a gas suspension calciner. Applied Clay Science 103: 10-19.

10. Salvador S (1995) Pozzolanic properties of flash-calcined kaolinite: A comparative study with soak-calcined products. Cement and Concrete Research 25(1): 102-112.

11. Siddique R, Klaus J (2009) Influence of metakaolin on the properties of mortar and concrete: A review. Applied Clay Science 43(3-4): 392-400.

For possible submissions Click below: 